Moralı, G. ve Göçer, A. (2019). Yabancı dil olarak Türkçe öğretiminde kültür paylaşımına yönelik öğretmen görüşleri. Ana Dili Eğitimi Dergisi, 7(4), 1115-1129.

\begin{tabular}{c}
$\begin{array}{c}\text { Ana Dili Eğitimi Dergisi } \\
\text { Journal of Mother Tongue Education } \\
\text { www.anadiliegitimi.com }\end{array}$ \\
$\begin{array}{c}\text { Geliş/Received: } 22.08 .2019 \text { Kabul/Accepted:29.10.2019 } \\
\text { Araştirma Makalesi / Research Paper }\end{array}$ \\
\hline
\end{tabular}

\title{
Yabancı Dil Olarak Türkçe Öğretiminde Kültür Paylaşımına Yönelik Öğretmen Görüşleri*
}

\author{
Gürkan MORALI** \\ Ali $G O ̈ C ̧ E R^{* * *}$
}

\begin{abstract}
Öz
Türkçenin yabancı dil olarak öğretimi, çok boyutlu bir süreçtir. Bu süreçte öncelikle dilin öğretimi ön plana çıkmaktadır. Ancak bu sürece dâhil olan farklı bileşenler de bulunmaktadır. Bu bileşenlerden biri de kültürdür. Bu bağlamda çalışmanın amacı, yabancı dil olarak Türkçe öğretiminde öğretmenlerin kültür aktarımına yönelik görüşlerini incelemektir. Nitel araştırma yaklaşımı çerçevesinde gerçekleştirilen çalışmada, görüşme formlarıyla elde edilen ve öğretmen görüşlerini yansıtan veriler incelenmiştir. Verilerin analizinde Miles ve Huberman'ın (2015) etkileşimli modeli kullanılmıştır. Araştırmada elde edilen bulgulara göre öğretmenlerin kültür aktarımında materyal yeterliği konusunda farklı görüşlere sahip oldukları, derslerinde çeşitli kültür aktarım yollarını benimsedikleri, sınıf içi öğrenme boyutunda öğrencilerin Türk kültürünü öğrenmeye istekli oldukları, Türk kültürüne yaklaşımlarının genellikle olumlu olduğu, kitaplarda ise kültür aktarımına daha fazla yer verilmesi gerektiği sonucuna ulaşılmıştır. Araştırma sonuçlarına göre yabancı dil olarak Türkçe öğretiminde öncelikli olarak ders kitaplarındaki kültürel unsurların zenginleştirilmesi önerilmektedir.
\end{abstract}

Anahtar Kelimeler: yabancı dil olarak Türkçe öğretimi, kültür, kültür aktarımı, öğretmen

Teachers' Views on the Teaching of Culture in Teaching Turkish as a Foreign Language

\begin{abstract}
Teaching Turkish as a foreign language is a multidimensional process. In this process, teaching of the language becomes prominent. However, various other components are involved in the process as well. One of these components is culture. The aim of this study is to examine teachers' views on teaching culture in teaching of Turkish as a foreign language. In the study which was conducted using one of the qualitative research methods, namely, the interview method, data which were obtained through interview forms and consisted of teachers' views were analyzed. Miles and Huberman's (2015) interactive model was used in the analysis of the data. According to the findings of the study, it was found that teachers had different opinions on the adequacy of the materials in terms of teaching culture, that they adopted different ways in teaching culture, that the students in classes were willing to learn the Turkish culture, that the students' approach to the Turkish culture was generally positive and that the teaching of culture should be included more in course books. Based on the findings, it is recommended that, in teaching Turkish as a foreign language, cultural elements in course books should primarily be enriched.
\end{abstract}

Keywords: Teaching Turkish as a foreign language, culture, culture teaching, teacher

\footnotetext{
* 25-27 Haziran 2019 tarihinde Nevşehir'de gerçekleştirilen “3. Uluslararası Eğitim Bilimleri ve Sosyal Bilimler Sempozyumu"nda sözlü olarak sunulan ve özet olarak yayınlanan "Yabancı Dil Olarak Türkçe Öğretiminde Kültür Aktarımına Yönelik Öğretmen Görüşlerinin Değerlendirilmesi” başlıklı bildirinin genişletilmiş hâlidir.

** Dr. Öğr. Üyesi, Erciyes Üniversitesi, Eğitim Fakültesi, Türkçe Öğretmenliği Bölümü, Kayseri, gurkanmorali@gmail.com, ORCID: 0000-0002-8539-7507

${ }_{* * *}$ Prof. Dr., Erciyes Üniversitesi, Eğitim Fakültesi, Türkçe Öğretmenliği Bölümü, Kayseri, gocer@erciyes.edu.tr, E-posta, ORCID: 0000-0002-6880-2611
} 


\section{Giriş}

Türkçenin yabancı dil olarak öğretimi, çok boyutlu bir süreçtir. Bu süreçte dilin öğretimi salt bir şekilde ön planda olmasına rağmen bu sürece dâhil olan birçok bileşen bulunmaktadır. Bu bileşenlerden biri de kültürdür.

Kültür, "tarihsel, toplumsal gelişme süreci içinde yaratılan bütün maddi ve manevi değerler ile bunları yaratmada, sonraki nesillere iletmede kullanılan, insanın doğal ve toplumsal çevresine egemenliğinin ölçüsünü gösteren araçların bütünüdür" (TDK, 2005, s. 1282). Dil ile kültür arasında kadim ve güçlü bir ilişki bulunduğu bilinmektedir. Dil, kültürün temel taşıyıcılarından biridir. Kültür, dil aracılığıyla nesillerden nesillere aktarılmakta ve yaşantısına devam etmektedir. Kültür bir anlamda dilin varlığını sağlayan itici güçtür. "Dil ve kültür, canlı bir beden vücuda getirir. Dil bedendir, kültür ise kandır" (Jiang, 2000, s. 328). Bu metafor, dil ile kültürün içe içe geçtiğini göstererek dilin kültürel bir boyutunun olduğunu yansıtmaktadır. Bu sebeple toplumun sahip olduğu birikimin birer göstergesi olan sözlü kültür unsurları, deyimler, atasözleri, etnografik malzemeler, halk kültürü ürünleri, yaşanmışlıklar, yemekler, giyim-kuşam vb. kültür unsurlarının karakteristik özellikleri ile tanıtılması, dil öğretiminde büyük önem taşımaktadır.

"Yabancı dil olarak Türkçe öğretiminde kültür aktarımı konusu ile ilgili çalışma yapan araştırmacılar, Türkçenin daha kalıcı ve etkili öğrenilebilmesi için dilin gramer özellikleri yanında kültüre ait öğelerin de anlatılması hususunda hemfikirdirler" (Elbir ve Aka, 2015, s. 383). Bu sebeple "kültür öğretimi, öğrencilerin Türk halkının yaşam tarzları, değerleri, tutumları ve inançlarıyla ilgili olarak Türk kültürü hakkındaki bilgilerini artırmaya olanak sağlamak için, Türkçe öğretiminin tamamlayıcı bir parçası olmalıdır" (Ökten ve Kavanoz, 2014, s. 859). Çünkü "modern dil öğretim yaklaşımlarında dil öğretiminin yanında o dili kullanan insanların kültürünün de öğretiminin başarıya ulaşmada önemli olduğu belirtilir" (Kalfa, 2013, s. 169).

Türkçenin yabancı dil olarak öğretiminde kültür farklı yollarla ve araçlarla öğretilmektedir. Bu öğretim şekli formal ve informal yollarla gerçekleşebilmektedir. Örneğin sınıf içi etkileşimde formal olabilirken düzenlenen bir gezide informal olabilir. Kültür öğretimi sürecinde öncelikle öğretmen unsuruna değinmek gerekir. Öğretmen, öğrencilerin kültürel farkındalık kazanmasında en önemli aktörlerden biridir. "Kültürü öğretmenin yollarını araştırmak, böylece kültür öğretimini öğrenciye kolaylaştırmak için çaba göstermek öğretmenin sorumluluğundadır” (İşcan, 2017, s. 439). Öğretmen sınıf ortamında kültürü hem temsil etmekte hem de uygun bağlamlarda öğrencilerin deneyimlemesi için çeşitli tasarımlar gerçekleştirmektedir. Sınıf içi kültür öğretiminde öğretmenin tutumu, yaklaşımı ve benimsediği öğretim metotları etkili olmaktadır. Örneğin öğretmenler, çok dilli ve çok kültürlü öğrenme ortamlarında yabancı dil olarak Türkçenin öğretiminde kültürlerarası yaklaşım, iletişimsel 
yaklaşım ve göreve dayalı dil öğretim yöntemlerini tercih ederek yaşantı temelli daha geçerli sonuçlar elde edebilmektedir. Bu yolla öğrencilerin kültür ile bağ kurmaları somut deneyimlerle sağlanabilmektedir.

Türkçenin yabancı dil olarak öğretiminde kültür etkileşimi sağlamada rol oynayan unsurlardan biri de kullanılan ders kitaplarıdır. Kitaplarda yer alan metinler, görseller ve farklı unsurlar öğrencilerin Türk kültürünü keşfetmesine birer uyaran olarak zemin hazırlamaktadır. Metinler deyim, atasözü, kalıp sözler gibi dilsel unsurların yanında kültüre ait farklı içerikler de barındırması bakımından kültür öğretiminde kullanılmaktadır. Yine metinlerdeki veya etkinliklerdeki sözel içeriği tamamlamak amacıyla kullanılan görseller de öğrencilerin hedef kültürü somutlaştırmalarına olanak sağlamaktadır. Öğrencilerin kültürel farkındalık kazanmalarını etkileyen unsurlardan biri de öğrenme ortamıdır. Öğrenme ortamında yer alan panolar ve duvarlardaki poster, afiş gibi görsel uyarıcılar öğrencilerin dikkatini kültüre çekme potansiyeline sahiptir. Kültüre ait çeşitli örnekleri bu yolla sunmak öğrencilerin hedef kültürü hem merak etmelerini hem de somutlaştırmalarını olanaklı hâle getirmektedir.

Türkçenin yabancı dil olarak öğretimi sürecinde hedef kitle büyük oranda farklı dil ve kültürden gelmekte ve çoğunlukla Türkçeyi öğrenme amacını taşıyan bireyler için hedef dil ikinci, üçüncü hatta dördüncü bir dil olabilmektedir. Bu çerçevede Türkçenin, çok dilli, çok kültürlü öğrenme ortamlarında öğretilmesi gündeme gelmektedir. Bu bağlamda kültür aktarımında dilin aracılık işlevi, medeniyetin imkânlarından beslenerek daha da artırılabilir. "Medeniyet çeşitli kültürlerin ortak taraflarını temsil ettiğine göre, bir cemiyet hem millî bir kültüre hem de müşterek bir medeniyete sahip olabilir" (Güngör, 1999, s. 80). Buradan hareketle Türkçenin öğretimi sürecinde kültürel farkındalık kazandırma çalışmalarının, hedef kitle ile kurulan köprü aracılığıyla ve ortak medeniyet unsurları zemininde gerçekleştirilmesi yararlı olacaktır. Çok dilli, çok kültürlü öğrenme ortamlarında öğretilmek istenen dilin ait olduğu kültürün somut olan ve somut olmayan unsurlarından mümkün olduğunca yararlanmak gerekir. Yalnız bu unsurlarının doğrudan tanıtılması yolu yerine kültürlerin birbirine benzer, ortak veya farklı yönlerinin ele alınarak işlenmesinde yarar vardır.

Türkçeyi öğrenmek isteyen hedef kitle çoğunlukla Türkiye'de eğitim amaçlı bulunan orta ve yükseköğretim öğrencilerinden oluşmaktadır. Bu öğrenciler başta eğitim olmak üzere farklı amaçlarla öğrenmek istedikleri Türkçeyi okul içinde ve farklı sosyal ortamlarda öğrenmeye çalışmaktadırlar. Öğrencilerin hedeflerine ulaşmaları için hem sınıf içi etkinliklerde hem de farklı sosyo-kültürel ortamlarda bulunmaları, eğitsel ve sportif etkinliklere katılmaları büyük önem taşımaktadır. Hedef dilin ait olduğu kültür ortamlarında öğrenilmesi, gerçek yaşama dönük kazanımlar açısından işlevsel bir görünüm kazanmaktadır. 
Yabancı dil olarak Türkçe öğretimi alanında kültürü ele alan çalışmaların genellikle ders kitapları ve metinler ile ilgili olduğu görülmektedir. Bu olgu Bayraktar (2015), Demir ve Açık (2011), Erdem, Gün ve Karateke (2015), Erdil (2018), İşcan ve Yassıtaş (2018), Kalenderoğlu (2015), Kutlu (2015), Okur ve Keskin (2013), Ökten ve Kavanoz (2014), Yılmaz (2012) gibi araştırmacılar tarafından gerçekleştirilen çalışmalarda da gözlenebilmektedir. Elbir ve Aka'nın (2015) yabancı dil olarak Türkçe öğretiminde kültür aktarımı ile ilgili çalışmaları değerlendirdikleri araştırmalarında, kültürün hem yüksek lisans tezlerinde hem de makalelerde ağırlıklı olarak ders kitapları ve metinler çerçevesinde ele alındığı tespit edilmiştir. Ancak yabancı dil olarak Türkçe öğretimi alanında kültür boyutunu, öğretmen ve öğrenci perspektifinden inceleyen çalışmalar konusunda eksiklik söz konusudur. Literatürde bu konudaki çalışmaların, kültür boyutunu ders kitapları ve metinler çerçevesinde ele alan çalışmaların gerisinde kaldığı görülmektedir. Bu çalışmada Türkçenin yabancı dil olarak öğretiminde öğretmenlerin kültür paylaşımına yönelik görüşlerinin incelenmesi amaçlanmıştır. Çünkü öğretim sürecinde öğretmen de önemli bir unsurdur. Öğretme sürecine rehberlik eden öğretmenlerin görüşlerinin alınması, yabancı dil olarak Türkçe öğretiminde hem kültür paylaşımına yönelik pratik bilgilerin yansıtılması hem de daha önce kültüre yönelik gerçekleştirilen çalışmalara farklı bir açıdan katkı sağlaması açısından önem arz etmektedir.

\section{Yöntem}

\section{Araştırmanın Modeli}

Bu çalışma, nitel araştırma yaklaşımı çerçevesinde görüşme yöntemiyle gerçekleştirilmiştir. "Görüşmenin temel amacı özel bilgi toplamaktır" (Merriam, 2013, s. 86). Bu araştırmada görüşmeler, öğretmenlerin yabancı dil olarak Türkçe öğretiminde kültür aktarımına yönelik kendi yaklaşımlarını belirleyebilmek için elverişli bir tür olmasından dolayı tercih edilmiştir. Çünkü her öğretmen, öğretim sürecinde kültür paylaşımına yönelik kendi yaklaşımını geliştirmiş ve kendine özgü bir bakış açısı inşa etmiştir.

\section{Katılımcılar}

Araştırmanın katılımcıları, İç Anadolu'daki bir devlet üniversitesinde yabancı uyruklu öğrencilere Türkçe hazırık kursu veren 8 öğretmenden oluşmaktadır. Katılımcıların 4'ü kadın, 4'ü ise erkektir. Her birinin mesleki kıdemi farklıdır. Çalışma deneyimi en az olan katılımcın 3 yıl, en fazla olan katııımcının ise 29 yıl çalışma süresi mevcuttur. Katılımcıların çalışma süreleri 3 ila 29 yıl arasında değişkenlik göstermektedir. Katılımcılardan biri araştırma görevlisi, diğerleri ise Türkçe hazırlık kursunda öğretim görevlisi ve MEB'de Türkçe öğretmeni olarak görev yapmaktadır. Öğretim görevlileri Türkçe hazırlık kursunda tam zamanlı çalışmakta diğer katılımcılar ise yarı zamanlı çalışmaktadır. 
Tablo 1. Katılımcılarla ilgili kişisel bilgiler

\begin{tabular}{lcc}
\hline Katılımcıların Cinsiyet Durumu & $f$ & $\%$ \\
\hline Kadın & 4 & 50.00 \\
Erkek & 4 & 50.00 \\
\hline Katılımcıların Unvanları/Görevleri & $f$ & $\%$ \\
\hline Öğretmen & 5 & 62.50 \\
Araştırma Görevlisi & 1 & 12.50 \\
Öğretim Görevlisi & 2 & 25.00 \\
\hline Katılımcıların Mesleki Kıdem Durumları & $f$ & $\%$ \\
\hline 0-5 yıl & 2 & 25.00 \\
6-10 yıl & 4 & 50.00 \\
21 ve üstü & 2 & 25.00 \\
\hline Toplam & 2 & 100,00 \\
\hline
\end{tabular}

\section{Veri Toplama Araçları}

Araştırmada öğretmenlerin görüşlerini tespit etmek için geliştirilen yarı yapılandırılmış görüşme formları, veri toplama aracı olarak kullanılmıştır. Araştırmadaki görüşme formları birer doküman olarak araştırmanın tek veri kaynağını oluşturmaktadır (Yıldırım ve Şimşek, 2013). Görüşme formları üç bölümden oluşmaktadır. Birinci bölümde araştırma hakkında bilgilendirme yapılmaktadır. Bu bölümde araştırmanın amacı, araştırma etiği ve araştırmacı hakkında bilgilere yer verilmektedir. İkinci bölümde ise katılımcılara ait tanımlayıcı bilgilerin kaydedildiği kısım bulunmaktadır. Bu bölümde katılımcıların cinsiyeti, unvanı ve kıdemi yer almaktadır. Üçüncü bölümde ise görüşme soruları yer almaktadır. Bu bölümde 5 adet açık uçlu soru yer almaktadır. Soruların devamında parantez içinde soru ile ilgili ipuçları oluşturacak anahtar kelimelere de yer verilmiştir. Bu yolla görüşme anında katılımcıların soruları anlamakta zorlandıkları anda ipuçları kullanılarak sorular tekrar sorulmuştur.

Görüşme soruları geliştirilirken araştırmanın gerçekleştirileceği kurumda çalışan, aynı zamanda yüksek lisans/doktora da yaptığı için bu alanda hem teorik hem de pratik bilgisi bulunan uzmanların kanısına başvurularak kapsam geçerliği hesaplanmıştır. Kapsam geçerliği hesaplanırken her sorunun altına 0-10 aralığı bulunan bir skala yerleştirilmiş ve uzmanlardan soruları araştırmanın amacına uygunluğunu göz önünde bulundurarak puanlamaları istenmiştir. Bu süreç sonunda her görüşme sorusuna ilişkin uzmanların ortak kanısı 0.7'nin üzerinde olduğu için geliştirilen sorular aynen kullanılmıştır. Görüşme sorularına yönelik kapsam geçerlik indeksi aşağıdaki tabloda gösterilmektedir.

Tablo 2. Uzmanların görüşme sorularına ilişkin puanları

\begin{tabular}{lllll}
\hline Görüşme Soruları & Uzman 1 & Uzman 2 & Uzman 3 & Puan \\
\hline Görüşme Sorusu 1 & 9 & 7 & 8 & 8 \\
Görüşme Sorusu 2 & 10 & 6 & 9 & 8.3 \\
Görüşme Sorusu 3 & 10 & 10 & 10 & 10 \\
Görüşme Sorusu 4 & 10 & 8 & 9 & 9 \\
Görüşme Sorusu 5 & 10 & 9 & 10 & 9.6 \\
\hline Ortalama & 9.8 & 8 & 9.2 & 8.98 \\
\hline
\end{tabular}




\section{İşlem / Verilerin Toplanması}

Verilerin toplanması sürecinde fiziksel görüşmeler gerçekleştirilmiştir. Bir haftalık süreçte öğretmenlerle derslerinin olduğu günler görüşülmüştür. Öğretmenlere görüşmenin ilk aşamasında, araştırmanın amacı ve niçin yapıldığı hakkında bilgi verilmiştir. Ayrıca öğretmenler, araştırma etiği ve kendilerine ait tanımlayıcı kişisel bilgileri paylaşmamaları hususunda bilgilendirilmiştir. Öğretmenlerin anlamlandırmakta zorlandıkları bir bölüm olursa araştırmacıya görüşme anında sorular sorabileceği de belirtilmiştir. Bilgilendirme aşamasından sonra öğretmenlerle görüşmelere geçilmiş ve veriler yazılı olarak kaydedilmiştir.

\section{Verilerin Analizi ve İnandırıcılığı}

Verilerin analizinde Miles ve Huberman'ın (2015) etkileşimli modeli kullanılmıştır. Bu model üç bileşenden oluşmaktadır: Veri azaltımı, veri gösterimi ve sonuç çıkarma/doğrulama. Aşă̆ıdaki şekilde etkileşimli model ve bileşenleri arasındaki ilişki görsel olarak sunulmaktadır.

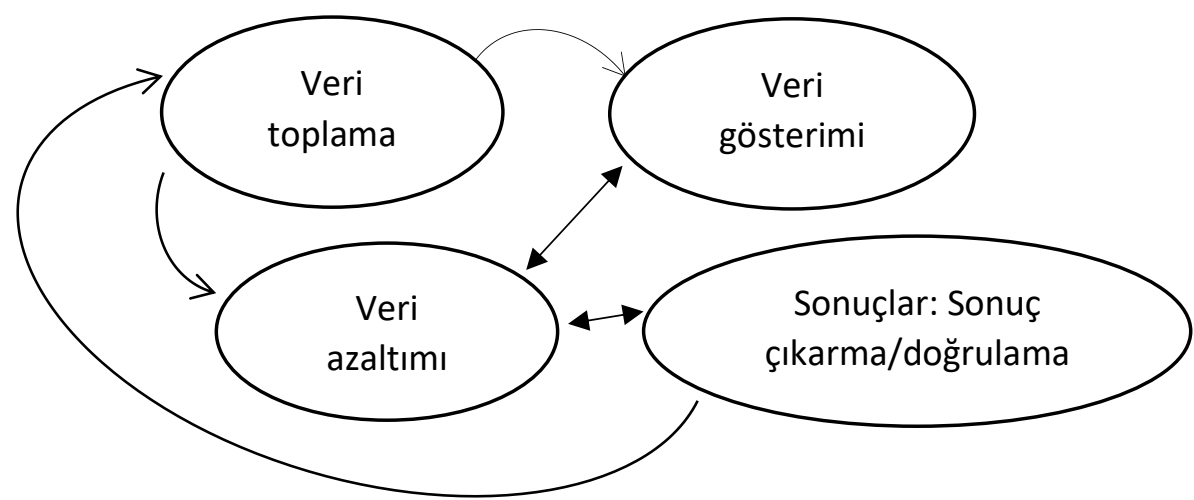

Şekil 1. Etkileşimli model (Miles ve Huberman, 2015, s. 12)

Etkileşimli modelde ilk bileşen verileri azaltmadır. Analiz boyunca eldeki verilere bu işlem uygulanmıştır (Punch, 2005). Sekiz adet dokümanda yer alan veriler tekrar tekrar incelenerek en anlamlı veriler ayrıştırılmıştır. Bu işlemin süreç boyunca yapılmasındaki amaç "verileri, önemli bir bilgi kaybına uğratmadan azaltmaktır" (Punch, 2005, s. 192). İkinci bileşende verilerin gösterimi gerçekleştirilmiştir. "Veri gösterimi, toplanan verilerin düzenlenmiş ve yoğunlaştırılmış hâlini yansıtmakta ve araştırma sonuçlarının ortaya konmasını sağlamaktadır" (Miles ve Huberman, 2015, s. 11). Bu aşamada, anlamlı veriler kod/temalar çerçevesinde tablolara yerleştirilmiştir. Bu yolla verilerin anlamlı bir çerçevede sunulması amaçlanmıştır. Son bileşende sonuç çıkarma/doğrulama işlemini gerçekleştirilmiştir. Bu aşamada araştırma sonuçlarının geçerliği test edilmiştir (Miles ve Huberman, 2015). Bu işlem sayesinde araştırma sonuçlarının inandırıcılığı sağlanmaktadır. İnandırıcılığı sağlamak için Miles ve Huberman'ın (2015) önerdiği kontrol kodlaması gerçekleştirilerek güvenirlik (=görüş birliği sayısı/toplam görüş birliği+görüş ayrılığı sayısıx100) hesaplanmıştır. İki araştırmacının kodları karşılaştırılarak gerçekleştirilen görüşmede tüm kodlar incelenmiş ve 21 kod üzerinde görüş birliği, 8 
kod üzerinde ise görüş ayrılığı tespit edilmiştir. Yapılan hesaplama sonucunda güvenirlik $\% 72$ olarak tespit edilmiştir. Ardından araştırmacılar görüş ayrıı̆ı̆na düşülen kodlar üzerinde düşüncelerini paylaşarak kodları yeniden yapılandırmıştır.

\section{Bulgular}

Bu bölümde araştırma kapsamında elde edilen veriler tablolar aracılığıyla yansıtılmaktadır. Her bir araştırma sorusuna ilişkin durum ayrı tablolar kullanılarak gösterilmektedir.

Tablo 3. Kullanılan ders kitabının kültür aktarımı açısından yeterlilik düzeyine ilişkin öğretmen görüşleri

\begin{tabular}{|c|c|c|}
\hline \multirow{2}{*}{$\begin{array}{l}\text { A : Kullandığınız ders kitabının kültür aktarımı açısından yeterlilik düzeyini } \\
\text { nasıl buluyorsunuz? }\end{array}$} & \multicolumn{2}{|c|}{ Kodlayarak Temalandırma } \\
\hline & Kodlar & Temalar \\
\hline $\begin{array}{l}\mathrm{K}_{3}: \text { Mevcut ders kitapları içinde en yeterli olan olarak düşünüyorum. } \\
\mathrm{K}_{6,8}: \text { Yeterli buluyorum. } \\
\mathrm{K}_{5} \text { : Orta derecede yeterli buluyorum. } \\
\mathrm{K}_{1} \text { : Ders kitaplarında kültür aktarımı görseller ve metinlerin içeriği ile } \\
\text { gerçekleşmektedir. Fakat bu aktarım yetersizdir. } \\
\mathrm{K}_{2} \text { : Kültür aktarımı istenilen ölçüde yer bulamıyor kitaplarda. } \\
\mathrm{K}_{4} \text { : Kullanılan ders kitabında Türk kültürü ile ilgili bilgiler var ama yetersiz } \\
\text { buluyorum. } \\
\mathrm{K}_{7} \text { : Kültür aktarımı açısından diğer yabancılara Türkçe öğretimi kitaplarına } \\
\text { göre daha iyi olmasına rağmen yeterli değildir. }\end{array}$ & yetersiz & $\begin{array}{l}\text { kültür aktarımında } \\
\text { materyal yeterliği }\end{array}$ \\
\hline
\end{tabular}

Katıımcılar kullandıkları ders kitabının kültür aktarımı açısından yeterlilik düzeyine ilişkin farklı görüşlere sahiptir. Ders kitabını kültür aktarımı açısından $K_{3,6,8}$ kodlu katılımcılar yeterli, $K_{5}$ kodlu katıımcı kısmen yeterli, $\mathrm{K}_{1,2,4,7}$ kodlu katılımcılar ise yetersiz bulmaktadır. $\mathrm{K}_{3}$ kodlu katılımcı diğer ders kitaplarını göz önünde bulundurarak kullandığı ders kitabını kültür aktarımı yönünden yeterli görürken $\mathrm{K}_{6,8}$ kodlu katılımcılar ders kitabını doğrudan yeterli olarak değerlendirmektedir. $\mathrm{K}_{5}$ kodlu katılımcı ders kitabının kültür aktarımı düzeyinin yeterliği konusunda net bir çıkarım yapamamakta ve kısmen yeterli olduğunu ifade etmektedir. $K_{1}$ kodlu katılımcı kültür aktarımı açısından görseller ve metinlerden yararlanıldığını ve $\mathrm{K}_{4}$ kodlu katılımcı Türk kültürü ile ilgili bilgilere yer verildiğini ifade etmelerine rağmen kültür aktarımının yetersiz olduğu görüşlerini paylaşmaktadır. $K_{2}$ kodlu katılımcıya göre ders kitabı kültür aktarımı yönünden beklentilerinin altında kalmaktadır. $K_{7}$ kodlu katılımcı, çıkış noktası olarak $K_{3}$ kodlu katılımcı ile aynı görüşü paylaşmasına rağmen ulaştığı yargı ders kitabını kültür aktarımı açısından yetersiz olduğu yöndedir.

Tablo 4. Ders içi etkinliklerde kültür aktarımına ilişkin öğretmen görüşleri

\begin{tabular}{lll}
\hline$A_{2}$ : Ders içi etkinliklerinizde kültür aktarımını nasıl gerçekleştirmektesiniz? & \multicolumn{2}{l}{ Kodlayarak Temalandırma } \\
\cline { 2 - 3 } & Kodlar & Temalar \\
\hline K1: Ders için kullandığımız ana materyal ders kitabıdır. & & kültür \\
K1: Kültür aktarımı gerçekleştiren metinlerde dersi, kültürümüzü anlatan & paylaşım \\
materyal (resim, video vb.) ile desteklemekteyiz. & metin kullanımı & yöntemleri \\
K3: Öncelikle ders kitaplarındaki görseller birer anahtar niteliğindedir. & \\
Görsellerden hareketle aktarım için uygun bir öğrenme ortamı doğmaktadır. & \\
Ayrıca günün/haftanın son dersinde eğlendirmek amacıyla kısa film veya & \\
videolar izlettirerek ve "şehir tanıtma" etkinliği adı altında coğrafi, tarihî ve &
\end{tabular}


kültürel değerleri aktarma adına fotoğraflarla gezinti yaparak kültür aktarımını gerçekleştirmeye çalışıyorum.

$\mathrm{K}_{4}$ : Ders kitabında Türk kültürüyle doğrudan ilgisi olsun ya da olmasın örneklerle, görseller kullanarak Türk kültürünü anlatıyorum.

$\mathrm{K}_{5}$ : Bazen sınıfa evden eşyalar getiriyorum (geleneksel eşyalar).

$\mathrm{K}_{6}$ : Genelde video kullanıyorum öğrencilere daha iyi anlatabilmek için.

$\mathrm{K}_{7}$ : Sınıfta görsel materyal ile ... öğretmekteyiz.

$\mathrm{K}_{2}$ : Konularla bağlantılı olarak Türk kültüründen örnekler verilmekte öğrencilerin kendi ülkelerindeki kültürel değerlerle karşılaştırma yapılmaktadır.

$\mathrm{K}_{4}$ : ...Bunun yanında daha iyi anlamaları için öğrencilerin kendi kültürleriyle karşılaştırma yapıyorum.

$\mathrm{K}_{6}:$...Bu eşyalar üzerinden geçmiş kültürel ögelere ait analiz ve karşılaştırma yapıp öğrencilerin de kendi kültürleriyle ilişkilendirmelerini istiyorum.

$\mathrm{K}_{1}$ : Bazen de öğretimi daha eğlenceli ve kalıcı yapmak adına sınıf içinde kültürümüzü anlatan bir küçük tiyatro (canlandırma) yapabilmekteyiz.

$K_{8}$ : Drama tekniğini kullanıyorum.

$\mathrm{K}_{8}$ : ...internetten faydalanıyorum. farklı

materyallerden

yararlanma

kültürlerarası

etkileşim

farklı öğretim

tekniklerinin

kullanımı

internet

kullanımı

Katılımcılar ders içi etkinliklerde kültür paylaşım yöntemlerine ilişkin farklı görüşlere sahiptir. $\mathrm{K}_{1}$ kodlu katılımcı kültür aktarımı açııından ders kitabından ve kitaptaki metinleri de desteklemek üzere farklı görsel materyallerden yararlanıldığını ifade etmiştir. $K_{3,4,5,6,7}$ kodlu katılımcılar, ders içi etkinliklerde kültür aktarımı gerçekleştirirken farklı materyalleri kullandıklarını belirtmişlerdir. Bu materyallerin görsellik yönünün ön planda olduğu vurgulanmıştır. $K_{2,4,6}$ kodlu katılımcılar ise kültürlerarası etkileşimi benimseyerek öğrencilere Türk kültürü ve kendi kültürleriyle ilişki kurabilecekleri bağlamlar sunmaktadır. Yine bu süreçte $K_{1}$ ve $K_{2}$ kodlu katılımcılar tiyatro ve drama gibi farklı öğretim tekniklerini kullandıklarını ifade etmiştir. $K_{8}$ kodlu katılımcı süreçte internetten faydalandığını da belirtmiştir.

Tablo 5. Öğrencilerin kültür unsurlarının konu edinildiği derslerdeki durumlarına ilişkin öğretmen görüşleri

\begin{tabular}{lll}
$\mathrm{A}_{3}$ : Öğrencilerin kültür unsurlarının konu edinildiği derslerdeki durumları & \multicolumn{2}{c}{ Kodlayarak Temalandırma } \\
\cline { 2 - 3 } konusundaki gözlemleriniz hakkında neler söylersiniz? & Kodlar & Temalar \\
\hline $\mathrm{K}_{1}, \mathrm{~K}_{2}, \mathrm{~K}_{3}, \mathrm{~K}_{5}, \mathrm{~K}_{6}, \mathrm{~K}_{7}, \mathrm{~K}_{8}$ : Öğrenciler bu gibi durumlarda oldukça isteklidir. & aktif katım \\
$\mathrm{K}_{1}$ : Kültürümüzü anlatan sınıf içi canlandırmalarda öğrenciler rol yapmak & & öğrenen \\
istemektedir. Derse katılım oranı daha fazla olmaktadır. & özellikleri & öğrenci \\
$\mathrm{K}_{4}:$ Türk kültürüne yakın toplumlardan gelen öğrenciler ile diğer toplumlardan & & merkezli \\
gelen çalışkan öğrenciler derslere daha ilgili ve alakalı oluyor. Tembel & kültürlerarası & sınıf ortamı \\
öğrenciler her ortamda isteksiz ve ilgisiz oluyor. & etkileşim & \\
$\mathrm{K}_{5}:$ Öğrenciler kendi kültürleriyle kıyaslandığında çok mutlu oluyorlar. Bu da & & \\
onların dil öğrenimlerinde daha aktif rol almasını sağlıyor. & duyuşsal \\
$\mathrm{K}_{8}:$ Merakla dinliyorlar ve kendi kültürleriyle karşılaştırıyorlar. & boyut \\
\hline
\end{tabular}

Katılımcılar, öğrencilerin kültür unsurlarının konu edinildiği derslerdeki durumları hakkında benzer görüşlere sahiptir. 7 katılımcı öğrencilerin bu tür derslerde istekli olduklarını belirtmiştir. $\mathrm{K}_{1,5}$ kodlu katıımcılar, öğrencilerin bu tür derslerde daha fazla aktif katılım sağladıklarını ifade etmiştir. Ayrıca katıımcılar öğrencilerin duyuşsal boyuta yönelik mutlu ve meraklı olduklarını da aktarmıştır. Öğrencilerin kendi kültürleriyle ilgili bir kıyaslamada bulunulmasının da sınıf içi öğrenci durumuna 
olumlu katkı yaptığı ifade edilmiştir. $K_{4}$ kodlu katılımcı öğrenen özelliklerinin etkili olduğunu belirterek Türk kültürüne yakın toplumlardan gelen öğrenciler ile diğer toplumlardan gelen çalışkan öğrencilerin daha ilgili ve alakalı olduklarını dile getirmiştir.

Tablo 6. Öğrencilerin Türk kültürüne yaklaşımına ilişkin öğretmen görüşleri

\begin{tabular}{|c|c|c|}
\hline \multirow{2}{*}{$\begin{array}{l}\text { A4: Öğrencilerin Türk kültürüne yaklaşımı konusunda neler } \\
\text { düşünmektesiniz? }\end{array}$} & \multicolumn{2}{|c|}{ Kodlayarak Temalandırma } \\
\hline & Kodlar & Temalar \\
\hline $\begin{array}{l}\mathrm{K}_{1}: \text { Öğrencilerimiz genellikle kıyafet konusunda büyük sorunlar } \\
\text { yaşamıyorlar. }\end{array}$ & & \\
\hline $\begin{array}{l}\mathrm{K}_{1} \text { : Yemek ve eğlence konusunda bazı sorunları yaşıyorlar. Örneğin Afrikalı } \\
\text { öğrencilerin Türk yemek kültürüne alışmaları uzun zaman alabiliyor. }\end{array}$ & giyim kuşam & \\
\hline $\begin{array}{l}\mathrm{K}_{2} \text { : Türk kültürüne yaklaşımları biraz ilgi alanlarıyla ilgili. Anlatılanla } \\
\text { sokaktaki karşılaşılan değerler bazen çatışmakta, şehir hayatının karmaşası } \\
\text { Türk kültürünün tanıtılmasını engellemektedir. Ayrıca Türk dizileri de } \\
\text { olumsuz etkenlerden sayılabilir. }\end{array}$ & eğlence tarzı & \\
\hline $\begin{array}{l}\text { K3: Büyük bir sıcaklık hissetmektedirler. Gerek Türklerin uluslararası } \\
\text { öğrencilere bakış açısı gerekse Müslüman olmamız öğrencilere hem büyük } \\
\text { bir özgüven veriyor hem de kendilerini rahat hissetmelerine zemin } \\
\text { hazırlıyor. }\end{array}$ & $\begin{array}{l}\text { uyuşma- } \\
\text { uyuşmazlık }\end{array}$ & $\begin{array}{l}\text { Türk kültür } \\
\text { unsurlarına } \\
\text { yönelik } \\
\text { öğrenci }\end{array}$ \\
\hline $\begin{array}{l}\text { K4:Yemek ve eğlence kültürü öğrencilerin dikkatini daha çok çekiyor. İnanç } \\
\text { konusu özel olduğu için çok benimsemiyorlar. }\end{array}$ & toplum yapısı & farkındalığı \\
\hline $\mathrm{K}_{5}$ : En çok etkili olan beden dili, inanç ve yemeklerdir. & mamç & \\
\hline $\begin{array}{l}\mathrm{K}_{6} \text { : Genelde sıcak ve misafirperver buluyorlar. } \\
\mathrm{K}_{7} \text { : Türk kültürünü öğrenciler merakla ve ilgiyle öğrenmeye }\end{array}$ & ilgi & \\
\hline $\begin{array}{l}\text { çalışmaktadırlar. Kendi kültürleri ve Türk kültürünü karşılaştırıp bizim } \\
\text { kültürümüzde farklı manaya geliyor şeklinde ifade etmektedirler. } \\
\text { K8: Türk kültürünü ilginç buluyorlar. Yemek ve giyim kuşam kültürü daha } \\
\text { çok ilgilerini çekiyor. }\end{array}$ & $\begin{array}{l}\text { kültürlerarası } \\
\text { etkileşim }\end{array}$ & \\
\hline
\end{tabular}

Katılımcılar, öğrencilerin Türk kültürüne yaklaşımları konusunda farklı görüşlere sahiptirler. $\mathrm{K}_{1,4,5,8}$ kodlu katılımcılar, öğrencilerin yemekler konusundaki yaklaşımlarını dile getirirlerken $\mathrm{K}_{1}$ kodlu katılımcı Afrikalı öğrencilerin yemek kültürüne uyum sağlamalarının zaman aldığını, $K_{4,8}$ kodlu katılımcılar yemek kültürünün öğrencilerin dikkatlerini ve ilgilerini çektiğini ve $K_{5}$ kodlu katılımcı yemek kültürünün öğrenci yaklaşımında etkili bir unsur olduğunu belirtmişlerdir. $K_{2}$ kodlu katılımcı öğrenci yaklaşımlarında bireysel unsurların etkili olduğuna dikkat çekmiştir. İlaveten derste anlatılanlar ile sokakta karşılaşılanlar arasındaki farklılıklar kültür aktarımını olumsuz etkileyen unsurlar olarak belirtilmiş ve süreçteki olumsuz etkenlerden birinin de diziler olduğu aktarılmıştır. $K_{3}$ kodlu katıımcı öğrencilerin Türk kültürüne yaklaşımının olumlu olduğunu ve Türk kültürüne karşı sıcak hissettiklerini ifade etmiştir. $K_{6}$ kodlu katılımcı da benzer görüşlere sahiptir. $K_{2}$ kodlu katılımcı bu durumun oluşmasında etkili olan faktörlerin, Türklerin uluslararası öğrencilere yaklaşımı ve dini inanç olduğunu belirtmiştir. $K_{4}$ kodlu katılımcı ise inanç konusunun öğrenci yaklaşımında olumsuz bir faktör olduğunu vurgulamıştır. Türklere özgü inançları, inançların özel bir durum olması sebebiyle öğrencilerin tabii olarak benimsemediklerine dikkat çekmiştir. $K_{4}$ kodlu katılımcı eğlence kültürünün öğrencilerin dikkatini çektiğini belirtmesine rağmen $\mathrm{K}_{1}$ kodlu katılımcı öğrencilerin eğlence kültürü ile bazı sorunlar yaşadığını ifade etmiştir. $K_{8}$ kodlu katıımcı, öğrencilerin giyim kültürünün de öğrencilerin ilgisini 
çektiğini belirtmiş, $\mathrm{K}_{1}$ kodlu katılımcı ise öğrencilerin bu konuda büyük sorunlar yaşamadıklarına dikkat çekmiştir. $K_{7}$ kodlu katılımcı öğrencilerin Türk kültürüne merakla yaklaştıklarını, kültürlerarası yaklaşım benimseyerek kendi kültürleri ile Türk kültürünü karşılaştırma eğiliminde olduklarını dile getirmiştir.

Tablo 7. Hangi kültür unsurlarına yer verilmesine ilişkin öğretmen görüşleri

\begin{tabular}{|c|c|c|}
\hline \multirow{2}{*}{$\begin{array}{l}\text { As: Yabancı dil Türkçe öğretiminde kullanılacak materyallerde hangi kültür } \\
\text { unsurlarına yer verilmesini istersiniz? }\end{array}$} & \multicolumn{2}{|c|}{ Kodlayarak Temalandırma } \\
\hline & Kodlar & Temalar \\
\hline $\begin{array}{l}\mathrm{K}_{1,2,4,5} \text { : Ders kitaplarında Türk kültürünü anlatan ve aktaran daha fazla konuya } \\
\text { yer verilmeli. } \\
\mathrm{K}_{1}: \text { Türk bilim adamlarını anlatan metinler olabilir. } \\
\mathrm{K}_{3} \text { : Kullanılacak materyallerin Türk İslam kültürüne ait ögelerden oluşması } \\
\text { gerektiğini düşünüyorum. } \\
\mathrm{K}_{7} \text { : Ders materyallerinde kültüre ait resimlere, Türk dizi veya şiirlerine yer } \\
\text { verilmelidir. } \\
\mathrm{K}_{8} \text { : Giyim kuşam, yemek ve mimariye daha çok yer verilebilir. }\end{array}$ & $\begin{array}{l}\text { içeriği } \\
\text { zenginleştirme } \\
\text { Türk-islam } \\
\text { unsurlarının } \\
\text { kullanımı } \\
\text { görsellik } \\
\text { günlük hayatı } \\
\text { yansıtma }\end{array}$ & $\begin{array}{l}\text { kültürel } \\
\text { unsur } \\
\text { çeşitliliği }\end{array}$ \\
\hline
\end{tabular}

$\mathrm{K}_{1,2,4,5}$ kodlu katılımcılar ders kitaplarındaki içeriğin zenginleştirilmesi fikrini öne sürerek ders kitaplarında Türk kültürünü anlatan ve aktaran daha fazla konuya yer verilmesi gerektiğini ifade etmiştir. $K_{1}$ kodlu katılımcı Türk bilim adamlarını anlatan metinlere yer verilmesi düşüncesini paylaşmıştır. $K_{3}$ kodlu katılımcı kullanılacak materyallerde Türk-İslam unsurlarının yer alması gerektiğini ifade etmiştir. $K_{7}$ kodlu katılımcı görselliği ön plana çıkararak ders materyallerinde kültüre ait resimlere, Türk dizi veya şiirlere yer verilmesi fikrini paylaşmıştır. $\mathrm{K}_{8}$ kodlu katılımcı ise materyallerde günlük hayatın yansıtılması gerekliğine vurgu yaparak metinlerde giyim-kuşam, yemek ve mimari konularına daha fazla yer verilmesine dikkat çekmiştir.

\section{Tartışma, Sonuç ve Öneriler}

Yabancı dil öğrenen kişi kendini yabancı bir kültürün içinde bulur" (Seçkin Polat ve Dilidüzgün, 2015, s. 815). Çünkü "yabancı bir dili öğrenmeye çalışmak, o dilin kültürünü öğrenmeye çalışmakla eşdeğerdir" (Eryaman ve Kana, 2014, s. 218). Binlerce yıldır varlığını devam ettiren Türk kültürü, Türkçenin yabancı dil olarak öğrenimi ve öğretimi sürecinde etkin bir role sahiptir. Bu olgudan hareketle yabancı dil olarak Türkçe öğretiminin kültür boyutunu ele alan bu çalışmada, öğretmenlerin kültür aktarımına yönelik görüşleri çerçevesinde farklı bulgulara ulaşıımıştır.

Araştırma kapsamında kültür aktarımında öğretmenlerin ders kitabını önemsedikleri tespit edilmiştir. Öğretmenlerin bu algıya sahip olmasında ders kitabının ana materyal olarak kullanılmasının ve yabancı dil olarak Türkçe öğretiminin ders kitabı temelli yürütülmesinin etkili olduğu düşünülmektedir. Literatürdeki çalışmalar da bu kanıyı destekler niteliktedir. Çalışmalarda kültür aktarımı genellikle ders kitapları bağlamında ele alınmıştır. Örneğin Erdem, Gün ve Karateke (2015) C1 düzey İstanbul, Okur ve Keskin (2013) İstanbul setini, Kutlu (2015) B1-B2 düzey Gazi setini, İşcan ve Yassıtaş (2018) B1-B2 düzey Yedi İklim setini, Bayraktar (2015) Yeni Hitit 1 ve Kalenderoğlu (2015) temel düzey Gazi ve İstanbul setlerini incelemiştir. Öğretmen görüşlerine göre ana materyal olarak 
görülen ders kitapları kültür aktarımı konusunda yetersiz kalmaktadır. Öğretmenlerin ifade ettiği bu görüşü, literatürdeki çalışmalar destekler niteliktedir. Karababa ve Üstünsoy Taşkın (2012), “öğretmen görüşlerine göre Yeni Hitit Yabancılar İçin Türkçe ders kitaplarının Türk kültürünü ve edebiyatını tanıtan metinlere yer verme bakımından yetersiz bulunduğunu" (s. 65) tespit etmiştir. Okur ve Keskin (2013) tarafından "temel seviye kitaplarında kültürel ögelerden az yararlanıldığı tespit edilmiş, orta seviye ders kitaplarında bu öğelere daha fazla yer verilmesine rağmen kültürel ögelerden daha fazla yararlanması gerektiği düşüncesi oluşmuştur" (s. 1639). Ökten ve Kavanoz (2014), yabancı dil olarak Türkçe öğretiminde kullanılan kitapları inceledikleri çalışmada, "kitaplarda sunulan Türk kültürüne ait ögelerin kültürlerarası öğrenmeyi desteklemede yetersiz kaldığı” (s. 858) sonucuna ulaşmıştır. Kutlu (2015), Gazi Üniversitesi TÖMER'in B1-B2 seviyesi kitaplarını incelediği çalışmasında ise kitaplarda kültürel ögelere yer verildiğini tespit etmesine rağmen bu hususta eksik bazı konuları belirleyerek güncellenen baskılarda bu eksikliklerin giderilmesi önerisinde bulunmuştur (s. 707). Erdil (2018) ise araştırmasında "Türkçe okutmanlarının, A1 İstanbul Yabancılar için Türkçe Ders Kitabını kültür aktarımı alanında yetersiz bulduğunu" (s. 338) tespit etmiştir.

Araştırma kapsamında elde edilen diğer bir bulgu da öğretmenlerin Türk kültürünü öğretirken farklı materyalleri kullanarak değişik aktarım yollarına başvurduklarıdır. Bu yollardan biri metinlerin kullanımıdır. "Çünkü metinler yoluyla gündelik yaşamın daha iyi kavranması ve öğrencinin içinde yaşadığı topluma uyum sürecini hızlandırması kolaylaşacaktır. Bu da yabancı dilin daha etkin kullanımını sağlayacaktır" (Bölükbaş ve Keskin, 2010, s. 229). Öğretmenlerin Türk kültürünü aktarırken başvurdukları yollardan biri de video, kısa film, resim gibi görsel unsurları kullanmalarıdır. İşcan’a (2011) göre "günümüzde kültürel unsurların yansıtılmasında en önemli araçlardan biri de hiç şüphesiz filmlerdir" (s. 946). "Dolayısıyla, kurgu ve içerik bakımından Türk tarihini, kültürünü ve toplumunun gerçek yaşamını en iyi şekilde yansıtan Türk filmleri de yabancı dil olarak Türkçe öğretiminin en önemli araçlarından biridir" (İşcan, 2011, s. 946). Ayrıca öğretmenlerin bu süreçte gerçek eşyalardan, internetten yararlandıkları, öğrencilerin fiziksel olarak katıımını da teşvik eden tiyatro, drama gibi farklı öğretim tekniklerini kullandıkları ve öğrencileri için kültürlerarası bir bağlam oluşturdukları da tespit edilmiştir.

Kültür unsurlarının konu edinildiği derslerde sınıf içi öğrenci durumları konusunda öğretmenlerin neredeyse tamamı öğrencilerin istekli olduklarını ifade etmiştir. Gün (2015) de "sınıf ortamında Türk kültürüne ilişkin ögelerin kullanılmasının, Suriyeli öğrencilerin Türkçeye karşı güdülenmelerini artırdığını” (s. 134) tespit etmiştir. Öğretmen görüşlerine göre öğrencilerin derse katılım oranının daha fazla olduğu, derslere aktif olarak katıldıkları, merakla dinledikleri ve mutlu hissettikleri de ortaya çıkmıştır. Gün (2015) tarafından gerçekleştirilen araştırmada da "yeni bir kültürü öğrenmeye meraklı olan öğrencilerin dil öğrenmede daha aktif rol aldıkları" (s. 134) bulunmuştur. 
Ayrıca öğretmen görüşlerine göre Türk kültürüne yakın toplumlardan gelen öğrenciler ve diğer toplumlardan gelen çalışkan öğrenciler derslere yönelik daha fazla ilgi göstermekte ancak tembel öğrenciler isteksiz ve ilgisiz davranmaktadır. Kültür unsurlarının konu edinildiği derslerde öğrenen özelliklerinin de belirleyici olduğu düşünülmektedir.

Öğrencilerin Türk kültürüne yaklaşımları konusunda farklı görüşlerin olduğu ortaya çıkmıştır. Yemek ve eğlence kültürünün öğrencilerin dikkatini çektiği ancak öğrencilerin bir kısmının yemek kültürüne uyum sağlamasının zaman aldığı ve eğlence kültürü ile bazı sorunlar yaşadığını tespit edilmiştir. Yemek ve eğlence kültürüne yönelik tespit, literatürdeki bilgilerle örtüşmektedir. Güleç ve İnce (2013) tarafından gerçekleştirilen çalışmada da “öğrencilerin yemek ve eğlence gibi konularda orta düzeyde bir problem yaşadıkları" (s. 95) tespit edilmiştir. Giyim kültürünün de öğrencilerin ilgisini çektiği belirtilmiş ve öğrencilerin bu konuda büyük sorunlar yaşamadıklarına dikkat çekilmiştir. Güleç ve İnce (2013) de benzer bir şekilde “öğrencilerin kıyafet konusunda büyük sorun yaşamadıklarını” (s. 95) aktarmıştır. Öğrenci yaklaşımlarında bireysel unsurların etkili olduğuna dikkat çekilerek derste anlatılanlar ile sokakta karşılaşılanlar arasındaki farklılıklar kültür aktarımını olumsuz etkileyen unsurlar olarak belirtilmiş ve süreçteki olumsuz etkenlerden birinin de diziler olduğu aktarılmıştır. Kırbaş ve Doğanay (2015) Ürdün Üniversitesinden katılımcılarla gerçekleştirdikleri çalışmada, “öğrencilerin görüşlerine göre kültür tanıtımı açısından dizi ve filmlerin Türk kültürünü yeterli düzeyde tanıtamadığını” (s. 1059) tespit etmiştir. Ayrıca bu araştırmada öğrencilerin Türk kültürüne yaklaşımının olumlu olduğu ve Türk kültürüne karşı sıcak hissettikleri ifade edilmiştir. Bu durumun oluşmasında etkili olan faktörlerin, Türklerin uluslararası öğrencilere yaklaşımı ve dini inanç olduğu belirtilmiştir. Bu bulguya zıt olarak inanç konusunun öğrenci yaklaşımında olumsuz bir faktör olduğu da ortaya çıkmıştır. Öğrencilerin Türk kültürüne merakla yaklaştıkları, kültürlerarası yaklaşım benimseyerek kendi kültürleri ile Türk kültürünü karşılaştırma eğiliminde oldukları da dile getirilmiştir.

Öğretmen görüşlerine göre ders kitaplarındaki içeriğin zenginleştirilmesi, ders kitaplarında Türk kültürünü anlatan ve aktaran daha fazla konuya yer verilmesi gerektiği ortaya çıkmıştır. Bu kapsamda Türk bilim adamlarını anlatan metinlere, Türk-İslam unsurlarına, ders materyallerinde kültüre ait resimlere, materyallerde günlük hayatın yansıtılması gerekliğine vurgu yapılarak metinlerde giyim-kuşam, yemek ve mimari konularına daha fazla yer verilmesi ve görselliğin ön plana çıkarılması görüş olarak ifade edilmiştir.

Bu araştırmada elde edilen sonuçlara göre mevcut ders kitaplarının kültürel içerik bakımından zenginleştirilmesi, ders kitaplarında daha çok kültürel unsurlara yer verilmesi ve kültür aktarımında çeşitli materyallerden yararlanılarak farklı öğretim tekniklerinin kullanılması önerilmektedir. Bu öneriler dikkate alındığında "Türkçeyi yabancı dil olarak öğrenenlerde sıkça karşılaşılan sorunlardan biri olan kültürel bilgi eksikliğinin" (Erdem, 2011, s. 121) önemli ölçüde önüne geçileceği düşünülmektedir. 
Çünkü kültürel bilgi, yabancı dil olarak Türkçe öğrenen bireylerin günlük iletişim intiyaçlarını gidermesinde önemli bir role sahiptir. Günlük hayatta dil ile kültür iç içe olduğu için kültürel bilgi, öğrencilerin iletişim becerilerinin anlamlı ve etkili olmasını sağlamaktadır. Bu yüzden yabancı dil Türkçe öğrencilerinin iletişimsel süreçleri verimli bir şekilde yürütebilmeleri için kültüre ait kazanımları da edinmeleri bir ihtiyaç olarak algılanmalıdır.

\section{Kaynaklar}

Bayraktar, S. (2015). Yeni Hitit 1 yabancılar için Türkçe ders kitabının kültür aktarımı açısından incelenmesi. Hacettepe Üniversitesi Yabancı Dil Olarak Türkçe Araştırmaları Dergisi, 2, 7-23. Retrieved from http://dergipark.org.tr/huydotad/issue/37784/436227

Bölükbaş, F., \& Keskin, F. (2010). Yabancı dil olarak Türkçe öğretiminde metinlerin kültür aktarımındaki işlevi. Turkish Studies, 5(4), 221-235.

Demir, A., \& Açık, F. (2011). Türkçenin yabancı dil olarak öğretiminde kültürlerarası yaklaşım ve seçilecek metinlerde bulunması gereken özellikler. Türklük Bilimi Araştırmaları, 30, 51-72.

Elbir, B., \& Aka, F. N. (2015). Yabancılara Türkçe öğretiminde kültür aktarımına yönelik yapılan çalışmaların değerlendirilmesi. Turkish Studies, 10(12), 371-386.

Erdem, B. (2011). Yabancı dil olarak Türkçe öğretiminde iletişim yeteneklerinin geliştirilmesine etkileşimsel toplumdilbilimsel bir yaklaşım. D. Yaylı ve Y. Bayyurt (Ed.), Yabancılara Türkçe öğretimi politika yöntem ve beceriler (2. bs.) içinde (ss. 115-142). Ankara: Anı Yayıncılık.

Erdem, M. D., Gün, M., \& Karateke, B. (2015). Illeri seviye için hazırlanan İstanbul yabancılara Türkçe öğretim setinin kültür aktarımı açısından incelenmesi. International Journal of Language Academy, 3(1), 8-17.

Erdil, M. (2018). Türkçe okutmanlarına ve yabancı öğrencilere göre İstanbul yabancılar için Türkçe ders kitaplarında (A1-A2) kültür aktarımı. International Journal of Languages' Education and Teaching, 6(1), 337-357.

Eryaman, M. Y., \& Kana, F. (2014). Yabancı dil olarak Türkçe öğretiminde program sorunu. A. Şahin (Ed.), Yabancı dil olarak Türkçe öğretimi/Kuramlar, yaklaşımlar, etkinlikler içinde (ss. 207-226). Ankara: Pegem Akademi.

Güleç, İ., \& İnce, B. (2013). Türkçe öğrenen yabancıların günlük yaşama ilişkin kültürel algıları üzerine bir araştırma. Sakarya University Journal of Education, 3(3), 95-106.

Gün, M. (2015). Yabancılara Türkçe öğretimi veren öğretim elemanlarının Adıyaman ili çadır kent bölgesinde Türkçe öğrenen Suriyeli mültecilere Türk kültürü aktarımına ilişkin görüşleri. Cappadocia Journal of History and Social Sciences, 5, 119-138. http://dx.doi.org/10.18299/cahij.61

Güngör, E. (1999). Türk kültürü ve milliyetçilik (14. bs.). İstanbul: Ötüken Neşriyat.

İşcan, A. (2011). Yabancı dil olarak Türkçe öğretiminde filmlerin yeri ve önemi. Turkish Studies, 6(3), 939-948.

İşcan, A. (2017). Yabancı dil olarak Türkçe öğretiminde kültür aktarım aracı olarak filmlerden yararlanma. Türkiyat Araştırmaları Enstitüsü Dergisi, 58, 437-452.

İşcan, A., \& Yassıtaş, T. (2018). Yabancı dil olarak Türkçe öğretimi ders kitaplarında kültür aktarımı: Yedi iklim Türkçe öğretim seti örneği (B1-B2 düzeyi). Aydın TÖMER Dil Dergisi, 3(1), 47-66. Retrieved from http://dergipark.org.tr/aydintdd/issue/36339/400678

Kalenderoğlu, İ. (2015). Türkçenin yabancı dil olarak öğretiminde kullanılan temel düzey (A1, A2) ders kitaplarında kültür aktarımı. 21. Yüzyılda Eğitim ve Toplum, 4(12), 73-83. Retrieved from http://dergipark.org.tr/egitimvetoplum/issue/32107/355906 
Kalfa, M. (2013). Yabancılara Türkçe öğretiminde sözlü kültür unsurlarının kullanımı. Millî Folklor, 25(97), 167177.

Karababa, Z. C., \& Üstünsoy Taşkın, S. (2012). Yabancı dil olarak Türkçe öğretiminde kullanılan ders kitaplarının öğretmen görüşleri çerçevesinde değerlendirilmesi. Dil Dergisi, 157, 65-80.

Kırbaş, G., \& Doğanay, H. (2015). Yabancı dil olarak Türkçe öğretimi/öğreniminde dizi ve filmler. International Journal of Languages' Education and Teaching, UDES 2015, 1052-1061.

Kutlu, A. (2015). Yabancılara Türkçe öğretiminde kültürün araç olarak kullanımı: Gazi yabancılar için Türkçe öğretim seti örneği (B1-B2 Seviyesi). Kastamonu Eğitim Dergisi, 23(2), 697-710.

Jiang, W. (2000). The relationship between culture and language. ELT journal, 54(4), 328-334.

Merriam, S. B. (2013). Nitel araştırma: Desen ve uygulama için bir rehber (Çev. ed.: S. Turan). Ankara: Nobel Yayıncılık.

Miles, M. B., \& Huberman, A. M. (2015). Genişletilmiş bir kaynak kitap: Nitel veri analizi (Çev. Ed., S. Akbaba Altun ve A. Ersoy). Ankara: Pegem Akademi.

Okur, A., \& Keskin, F. (2013). Yabancılara Türkçe öğretiminde kültürel ögelerin aktarımı: İstanbul yabancılar için Türkçe öğretim seti örneği. The Journal of Academic Social Science Studies, 6(2), 1619-1640.

Ökten, C. E., \& Kavanoz, S. (2014). Yabancı dil olarak Türkçe öğretimini hedefleyen ders kitaplarında kültür aktarımı. Turkish Studies, 9(3), 845-862.

Punch, K. F. (2005). Sosyal araştırmalara giriş (Çev. D. Bayrak, H. B. Arslan ve Z. Akyüz). Ankara: Siyasal Kitabevi.

Seçkin Polat, Ö., \& Dilidüzgün, Ş. (2015). Yabancı dil olarak Türkçe öğretiminde şiir etkinliklerinin kültürel işlevi. Turkish Studies, 10(7), 815-834.

TDK (2005). Türkçe sözlük (10. bs.). Ankara: TDK Yayınları.

Yıldırım, A., \& Şimşek, H. (2013). Sosyal bilimlerde nitel araştırma yöntemleri (Genişletilmiş 9. bs.). Ankara: Seçkin Yayıncilık.

Yılmaz, F. (2012). Cultural transmission through teaching Turkish as a foreign language course books. Turkish Studies, 7(3), 2751-2759.

\section{Extended Abstract}

Introduction

Teaching Turkish as a foreign language is a multidimensional process. Although language teaching is Teaching Turkish as a foreign language is a multidimensional process. In this process, teaching of the language becomes prominent. However, various other components are involved in the process as well. One of these components is culture. Culture "is the totality of all material and moral values created in the historical and social development process of a society and the means that are used to create and transmit them to future generations which show the extent of human superiority over the natural and social environment" (TDK, 2005, p. 1282). It is known that there is an ancient and strong relationship between language and culture. Language is one of the main means of transmitting culture. Culture is transmitted from older generations to younger generations through language and continues to live. In a sense, culture is the driving force for the existence of language.

"Researchers who work on the subject of cultural transfer in teaching Turkish as a foreign language agree that the elements of culture should be taught besides the grammatical features of the language in order for learners to learn Turkish more permanently and effectively "(Elbir \& Aka, 2015, p. 383). Therefore, "culture instruction should be an integral part of teaching Turkish in order to enable learners to increase their knowledge of the Turkish culture and the lifestyles, values, attitudes and beliefs of the Turkish people" (Ökten \& Kavanoz, 2014 , p. 859). Because "in modern language teaching approaches, it is stated that besides language teaching, teaching the culture of the people using that language is also important for success (Kalfa, 2013, p. 169).

Method

This study was conducted using the interview method which is a part of the qualitative research paradigm. "The main purpose of the interview is to collect private information" (Merriam, 2013, p. 86). In this research, the interview method was preferred because it conveniently enabled the researchers to determine 
teachers' individual approaches to teaching culture in teaching Turkish as a foreign language as each teacher developed his own approach and built his own perspective.

\section{Result and Discussion}

In the study, it was determined that teachers attached importance to course book in teaching culture. It is thought that the use of the course books as the main material and the teaching of Turkish as a foreign language based solely on course books are influential for teachers to develop this impression. Studies in the literature support this opinion. As the main instructional materials, the participating teachers in this study considered course books inadequate in terms of teaching culture. This view expressed by the teachers is supported by studies in the literature.

Another finding obtained in the research is that teachers used different materials while teaching the Turkish culture. Almost all of the teachers stated that their students displayed eagerness when cultural elements were covered in classes. Gün (2015) found that "the use of elements related to the Turkish culture in the classroom environment increased the motivation of Syrian students toward Turkish" (p. 134). According to the teachers, students participated at a higher rate, participated actively, listened attentively and felt happy when culture was taught. In addition, according to teachers, students who were members of the societies that were close to the Turkish culture and hardworking students from other societies showed more interest in classes, but lazy students were reluctant and indifferent. It was found that the characteristics of the learners were also influential in the acquisition of cultural elements.

It was also found that the students had different views on the Turkish culture. It was found that food and entertainment culture attracted the attention of the students more, but it took time for some of the students to adapt to the food and some had problems adapting to the entertainment culture. The findings obtained are similar to the findings in studies with a similar perspective.

Based on the results obtained in this research, enriching the existing course books in terms of cultural content, including more cultural elements in the course books and using different teaching techniques by using various materials in culture teaching are recommended. 